\title{
Fine Mapping of Powdery Mildew Resistance Gene MIWE74 Derived From Wild Emmer Wheat (Triticum Turgidum ssp. Dicoccoides) in An NBS-LRR Gene Cluster
}

\section{Keyu Zhu}

IGDB: Institute of Genetics and Developmental Biology Chinese Academy of Sciences

Miaomiao Li ( $\sim$ mmli@genetics.ac.cn )

Institute of Genetics and Developmental Biology Chinese Academy of Sciences https://orcid.org/00000001-9691-0233

\section{Haibin Wu}

Academy of National Food and Strategic Reserves Administration

\section{Deyun Zhang}

chaozhou hybribio biochemistry Ltd

\section{Lingli Dong}

IGDB: Institute of Genetics and Developmental Biology Chinese Academy of Sciences

\section{Qiuhong Wu}

IGDB: Institute of Genetics and Developmental Biology Chinese Academy of Sciences

\section{Yongxing Chen}

IGDB: Institute of Genetics and Developmental Biology Chinese Academy of Sciences

Jingzhong Xie

IGDB: Institute of Genetics and Developmental Biology Chinese Academy of Sciences

Ping Lu

IGDB: Institute of Genetics and Developmental Biology Chinese Academy of Sciences

\section{Guanghao Guo}

IGDB: Institute of Genetics and Developmental Biology Chinese Academy of Sciences

Huaizhi Zhang

IGDB: Institute of Genetics and Developmental Biology Chinese Academy of Sciences

\section{Panpan Zhang}

IGDB: Institute of Genetics and Developmental Biology Chinese Academy of Sciences

\section{Beibei Li}

IGDB: Institute of Genetics and Developmental Biology Chinese Academy of Sciences

\section{Wenling Li}

IGDB: Institute of Genetics and Developmental Biology Chinese Academy of Sciences

\section{Lei Dong}


IGDB: Institute of Genetics and Developmental Biology Chinese Academy of Sciences

\section{Qifei Wang}

Zhejiang Academy of Agricultural Sciences

Jinghuan Zhu

Zhejiang Academy of Agricultural Sciences

\section{Wenli Hu}

Hebei gaoyi stock seed farm

\section{Liqiao Guo}

Hebei gaoyi stock seed farm

\section{Rongge Wang}

Hebei gaoyi stock seed farm

\section{Chengguo Yuan}

Hebei gaoyi stock seed farm

\section{Hongjie Li}

Chinese Academy of Agricultural Sciences Institute of Crop Sciences

\section{Zhiyong Liu}

IGDB: Institute of Genetics and Developmental Biology Chinese Academy of Sciences https://orcid.org/0000-0002-6958-5233

\section{Wei Hua}

Zhejiang Academy of Agricultural Sciences

\section{Research Article}

Keywords: Wheat powdery, genetic, geographical, environmental, disease

Posted Date: November 4th, 2021

DOI: https://doi.org/10.21203/rs.3.rs-1020649/v1

License: (c) (1) This work is licensed under a Creative Commons Attribution 4.0 International License. Read Full License

Version of Record: A version of this preprint was published at Theoretical and Applied Genetics on January 10th, 2022. See the published version at https://doi.org/10.1007/s00122-021-04027-2. 


\section{Fine mapping of powdery mildew resistance gene $M I W E 74$} derived from wild emmer wheat (Triticum turgidum ssp.

\section{dicoccoides) in an NBS-LRR gene cluster}

Keyu $\mathrm{Zhu}^{1,2}$, Miaomiao Li ${ }^{1, *}$, Haibin $\mathrm{Wu}^{3}$, Deyun $\mathrm{Zhang}^{4}$, Lingli Dong ${ }^{1}$, Qiuhong $\mathrm{Wu}^{1}$, Yongxing $\mathrm{Chen}^{1}$, Jingzhong Xie ${ }^{1}$, Ping $\mathrm{Lu}^{1}$, Guanghao Guo ${ }^{1,2}$, Huaizhi Zhang ${ }^{1,2}$, Panpan Zhang ${ }^{1,2}$, Beibei $\mathrm{Li}^{1,2}$, Wenling $\mathrm{Li}^{1,2}$, Lei Dong ${ }^{1,2}$, Qifei Wang ${ }^{5}$, Jinghuan $\mathrm{Zhu}^{5}$, Wenli $\mathrm{Hu}^{6}$, Liqiao $\mathrm{Guo}^{6}$, Rongge Wang ${ }^{6}$, Chengguo Yuan ${ }^{6}$, Hongjie $\mathrm{Li}^{7}$, Zhiyong Liu ${ }^{1,2, *}$, Wei Hua ${ }^{5, *}$

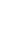

${ }^{1}$ State Key Laboratory of Plant Cell and Chromosome Engineering, Institute of Genetics and Developmental Biology, The Innovative Academy of Seed Design, Chinese Academy of Sciences, Beijing 100101, China

${ }^{2}$ University of Chinese Academy of Sciences, Beijing 100049, China

${ }^{3}$ Academy of National Food and Strategic Reserves Administration, Beijing 100037, China

${ }^{4}$ Chaozhou Hybribio Biochemistry Ltd., 521011, Guangdong, China

${ }^{5}$ Zhejiang Academy of Agricultural Sciences, Hangzhou, 310021, China

${ }^{6}$ Hebei Gaoyi Stock Seed Farm, Gaoyi 051330, Hebei, China

${ }^{7}$ The National Engineering Laboratory of Crop Molecular Breeding, Institute of Crop Sciences, Chinese Academy of Agricultural Sciences, Beijing 100081, China

* Corresponding authors, Email: mmli@genetics.ac.cn, zyliu@genetics.ac.cn, huaweicau@hotmail.com 


\title{
Abstract
}

\section{Key message}

Powdery mildew resistance gene $M I W E 74$, originated from wild emmer wheat accession G-748-M, was mapped in an NBS-LRR gene cluster of chromosome 2BS.

\begin{abstract}
Wheat powdery mildew, caused by Blumeria graminis f. sp. tritici (Bgt), is a globally devastating disease. Wild emmer wheat (Triticum turgidum var. dicoccoides) is a valuable genetic resource for improving disease resistance in common wheat. A powdery mildew resistance gene was transferred to hexaploid wheat line WE74 from wild emmer accession G-748-M. Genetic analysis revealed that the powdery mildew resistance in WE74 is controlled by a single dominant gene, herein temporarily designated MlWE74. Bulked segregant analysis (BSA) and molecular mapping delimited MlWE74 to the terminal region of chromosome 2BS flanking by markers WGGBD412 and $W G G B H 346$ within a genetic interval of $0.25 \mathrm{cM}$ and corresponding to 799.9 $\mathrm{kb}$ genomic region in the Zavitan reference sequence. Sequence annotation revealed two phosphoglycerate mutase-like genes, an alpha/beta-hydrolases gene, and five NBS-LRR disease resistance genes that could serve as candidates for map-based cloning of MlWE74. The geographical location analysis indicated that MlWE74 is mainly distributed in Rosh Pinna and Amirim regions, in the northern part of Israel, where environmental conditions are favorable to the occurrence of powdery mildew. Moreover, the co-segregated marker $W G G B D 425$ is helpful in marker-assisted transfer of MlWE74 into elite cultivars.
\end{abstract}




\section{Introduction}

Powdery mildew, caused by the fungal pathogen Blumeria graminis f. sp. tritici (Bgt), is one of the devastating diseases of wheat (Triticum aestivum L.) in areas with temperate climates. Breeding for resistance is the most economical and effective strategy to control powdery mildew. Up to now, more than a hundred powdery mildew resistance genes/alleles have been documented, and some of them have played important roles in stabilizing wheat yield, such as Pm21 (He et al. 2018; Xing et al. 2018), $\operatorname{Yr} 18 / \operatorname{Lr} 34 / \operatorname{Pm} 38 / \operatorname{Sr} 57$ (Krattinger et al. 2009), and Pm46/Yr46/Lr67/Sr55 (Moore er al. 2015). However, the emergence of new virulent pathotypes of Bgt reduces the resistance conferred by resistance $(R)$ genes (Singh et al. 2016). Recent studies indicated that Pm2, Pm3a, Pm3b, Pm3f, Pm4a,Pm6, Pm8, and $P m 17$ have been overcome in part or all of the USA, while Pm $1 a, P m 3 a$, and $P m 8$ were defeated in Australia, China, and Egypt (Parks et al. 2008; Cowger et al. 2018). Therefore, in response to the newly evolved Bgt virulent isolates, it is necessary to continuous search for new powdery mildew resistance genes.

Among the powdery mildew resistance genes that were currently reported, more than half of them are derived from diploid or tetraploid wild relatives of wheat including Aegilops squarrosa, Ae. speltoides, Ae. longissima, Ae. ovata, Dasypyrum villosum, T. urartu, T. turgidum var. dicoccoides, T. turgidum var. dicoccum, T. turgidum var. durum, T. timopheevii, T. monococcum, Thinopyrum intermedium, and cereal rye (Secale cereale L.) (http://wheat.pw.usda.gov/). The wild relatives of wheat are important sources for discovering wheat powdery mildew resistance genes. Transfer of alien genes is still an effective strategy for increasing the genetic diversity of powdery mildew resistance in wheat breeding. 
Wild emmer wheat (WEW), T. turgidum ssp. dicoccoides $(2 \mathrm{n}=4 \mathrm{x}=28$; genome AABB), is the wild progenitor of both cultivated tetraploid and hexaploid wheats. It carries many agronomically important traits that can be exploited for wheat improvement, e.g., quality attributes and disease resistances (Moseman et al. 1984; Nevo et al. 1991, 2014). Many powdery mildew resistance genes derived from wild emmer wheat have been discovered, for example, Pm26 (Rong et al. 2000), Pm42 (Hua et al. 2009), MllW170 (Liu et al. 2012), and MlIW39 (Qiu et al. 2021) on 2BS; Mlzecl (Mohler et al. 2005), MlAB10 (Maxwell et al. 2010), and Pm64 (Zhang et al. 2019) on 2BL; Pm41 (Li et al. 2009) on 3BL; MlIW30 (Geng et al. 2016) and MlNFS10 (Yin et al. 2021) on 4AL; Pm16 (Reader and Miller 1991) and Pm30 (Liu et al. 2002) that are possibly allelic on chromosome arm 5BS (Chen et al. 2005); Pm36 (Blanco et al. 2008) and Ml3D232 (Zhang et al. 2010) on 5BL; PmG3M (Xie et al. 2012) on 6BL; PmG16 (Ben-David et al. 2010), MlIW72 (Ji et al. 2008), MlIW172 (Ouyang et al. 2014), and MlWE18 (Wu et al. 2021) on 7AL. Among them, only Pm41 has been cloned, which encodes a typical CC-NBS-LRR protein (CNL) (Li et al. 2020).

Wild emmer wheat accession G-748-M is resistant to Bgt isolate E09. The powdery mildew resistance gene from this accession was transferred to hexaploid wheat by crossing and backcrossing with susceptible common wheat cultivars, resulting in common wheat line WE74 (YD1817/G-748-M//7*ND015). Line WE74 conferred highly resistance to Bgt isolate E09 at the seedling stage in the greenhouse and the adult plant stage in fields. The objectives of this study is to fine map the powdery mildew resistance gene in WE74, with an ultimate goal of cloning the powdery mildew resistance gene and providing breeders with friendly markers that can be used in marker-assisted breeding. 
Materials and methods

91

\section{Plant materials}

Wild emmer wheat accession G-748-M was kindly provided by Dr. ZK Gerechter-Amitai, Agricultural Research Organization, The Volcani Centre, Israel. G-748-M was resistant, with infection type (IT) 0, to Bgt isolates E09. Yanda 1817 and ND015 were used as susceptible parental lines for crossing and backcrossing to transfer resistance gene from G-748-M to common wheat, resulting in the powdery mildew resistant line WE74 (YD1817/G-748-M//7*ND015). WE74 was highly resistant to Bgt isolate E09 both at the seedling and adult growth stages. WE74 was crossed to the susceptible wheat Xuezao (XZ), developing $165 \mathrm{~F}_{2}$ plants and their $\mathrm{F}_{2: 3}$ families for genetic analyses and genetic mapping. A large $\mathrm{F}_{2}$ population including 2,107 plants from a cross between WE74 and $\mathrm{XZ}$ was used to construct a high-density linkage map. A collection of 461 wild emmer wheat accessions from different geographical collections were used to test the distribution of the powdery mildew resistance gene identified in WE74.

\section{Powdery mildew evaluations}

The parental lines WE74, XZ and the corresponding $F_{1}, F_{2}$ and $F_{2: 3}$ materials and the recombinant families from the mapping populations were evaluated for response to powdery mildew at two-leaf stage. The inoculated plants were grown under a daily cycle of $16 \mathrm{~h}$ of light and $8 \mathrm{~h}$ of darkness at $22 \pm 2{ }^{\circ} \mathrm{C}$ in a greenhouse. The resistant and susceptible parents were planted in the middle of each tray as the resistant and the susceptible controls, respectively. Seedlings with unfolded first leaves were inoculated with Bgt E09 by dusting of conidiospores. 
Infection types (ITs) were evaluated after $15 \mathrm{~d}$ on a scale of $0-4$, in which, 0,$0 ; 1,2,3$, and 4 represented immune, necrotic fecks, high resistance, moderate resistance, moderate susceptibility and high susceptibility, respectively. Phenotypes were classified into two groups, resistant (R, IT 0-2) and susceptible (S, IT 3-4) (Liu et al. 1999). WE74, IW170 and Pm26, carrying MlWE74, MlIW170 and Pm26 respectively, were also challenged by $10 \mathrm{Bgt}$ isolates collected from different regions of China.

\section{Genomic DNA isolation and marker analysis}

Genomic DNA was extracted from parental lines, $F_{2}$ plants, $F_{2: 3}$ families and wild emmer wheat accessions following the CTAB method (Devi et al. 2013). For bulked segregant analysis, separate DNA bulks were assembled using equal amounts of DNA from ten homozygous resistant and ten homozygous susceptible $\mathrm{F}_{2}$ plants, respectively. Wheat microsatellite markers (Xgwm, Xwmc, Xbarc, Xcfa, Xcfd and Xcau series) mapped on A and B genome chromosomes (Graingenes, http://wheat.pw.usda.gov/) were chosen for marker analyses. Polymorphic markers indicative of linkage with the powdery mildew resistance gene were further used to genotype the entire $\mathrm{F}_{2: 3}$ mapping population to determine genetic linkage between the gene and the markers. (Zhu et al. 2019), SSR, STS and InDel markers in the target region of the powdery mildew resistance gene were developed for linkage analysis. PCR was performed in a $10 \mu 1$ reaction mixture containing $5 \mu 12 \times$ Rapid Taq Master Mix (Vazyme, Nanjing, China), $1 \mu \mathrm{l}$ primer (mixture of left and right primers, $2 \mu \mathrm{M}$ ), $1 \mu \mathrm{l}$ DNA

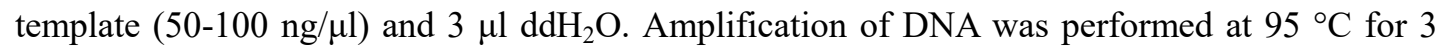


temperatures of primer pairs, and $72{ }^{\circ} \mathrm{C}$ for $15 \mathrm{sec} / \mathrm{kb}$, with a final extension at $72{ }^{\circ} \mathrm{C}$ for $5 \mathrm{~min}$. The PCR products $(3 \mu \mathrm{l})$ mixed with $2 \mu$ l loading buffer were separated on $8 \%$ non-denaturing polyacrylamide gels (39 acrylamide: 1 bisacrylamide). Gels were silver stained and photographed.

\section{Data analysis}

Genetic analysis was performed to examine the expected segregation ratios in the $F_{2}$ and $F_{2: 3}$ from WE74 $\times$ XZ populations using a Chi-squared $(\chi 2)$ test. MAPMAKER 3.0 (Lander et al. 1987) was used to construct a linkage map, with a LOD score of 3.0 as the threshold. The genetic map was drawn with the software Mapdraw V2.1 (Liu et al. 2003).

\section{Micro-collinearity analysis}

The nearest flanking markers of the powdery mildew resistance gene were used to obtain the genomic region of Chinese Spring (http://www.wheat-urgi.versailles.inra.fr/; IWGSC 2018) and durum wheat Svevo (https://www.interomics.eu/durum-wheat-genome; Maccaferri et al. 2019), hexaploid wheat cv. Fielder (https://shigen.nig.ac.jp/wheat/komugi/genome/download.jsp; Sato et al. 2021), Julius_MAGIC3, Landmark, Jagger, ArinalFor, Mattis, Longreach Lancer, Mace, Norin61 and spelt wheat PI 190962 (https://webblast.ipk-gatersleben.de/wheat_ten_genomes/; Walkowiak et al. 2020). The annotated genes of corresponding physical interval in these genomes were used for micro-collinearity analysis.

\section{Geographical distribution analysis}

A total of 461 accessions of wild emmer wheat collected from natural populations, representing a wide range of ecogeographic distribution of wild emmer wheat in Israel, Lebanon, Syria, Turkey and its vicinity were used to profile the distribution of the powdery mildew resistance gene. The 
co-segregating markers were used to detect the collection of wild emmer wheat.

\section{Results}

\section{Inheritance of powdery mildew resistance in WE74}

Genetic analysis was carried out to investigate the inheritance mode of powdery mildew resistance in WE74. WE74, XZ and $\mathrm{F}_{1}, \mathrm{~F}_{2}$, and $\mathrm{F}_{2: 3}$ progenies from the WE74 $\times \mathrm{XZ}$ cross were challenged by Bgt isolate E09 at the two-leaf stage. WE74 was resistant (IT 0), XZ was susceptible (IT 4), and the $F_{1}$ plants were resistant (IT 0;), indicating dominance of the resistance

(Fig. 1). We initially phenotyped $165 \mathrm{~F}_{2}$ plants, of which 120 were resistant and 45 were susceptible. The powdery mildew resistance was shown to segregate as a single dominant trait in the $F_{2}$ population (Table 1). To verify this result, the corresponding $F_{2: 3}$ progenies segregated as 38 homozygous resistant : 82 segregating : 45 homozygous susceptible families, fitting to the ratio 1:2:1. Therefore, these results indicate that the powdery mildew resistance in WE74 was controlled by a single dominant gene, temporarily designated MlWE74.

\section{Chromosomal location of MlWE74}

A total of 352 wheat SSR markers (Xgwm, Xwmc, Xbarc, Xcfa, Xcfd and Xcau) mapped to A and B genomes were screened for polymorphism between the resistant and susceptible $\mathrm{F}_{2}$ DNA bulks for bulked segregant analysis. Polymorphic SSR markers were selected to genotype the $165 \mathrm{~F}_{2}$ plants from WE74 $\times \mathrm{XZ}$ cross DNA samples. Nine polymorphic SSR markers, Xgwm210, Xgwm614, Xbarc297, Xcau357, Xwmc243, Xgwm257, Xbarc7, Xbarc55, and Xwmc477 were detected linked to MlWE74 (Table S1) and a genetic linkage map was constructed. All the 9 SSR markers were located on chromosome 2B (Fig. 2a). Gene MlWE74 was localized to a $1.8 \mathrm{cM}$ genetic interval between flanking markers Xcau357 and Xwmc243 at genetic distances of $1.2 \mathrm{cM}$ 
177 (distal) and $0.6 \mathrm{cM}$ (proximal), respectively (Fig. 2b). These results verified that the powdery

178 mildew resistance gene MlWE74 was located on chromosome arm 2BS.

179 Fine mapping of MlWE74

180 In order to construct a high-resolution genetic linkage map for the powdery mildew resistance 181 gene $M l W E 74$, a large segregating population including $2,107 \mathrm{~F}_{2}$ plants derived from the cross 182 between WE74 and XZ was developed. The two flanking molecular markers Xcau357 and $183 X w m c 243$ were used to genotype the entire $\mathrm{F}_{2}$ population, resulting in $76 \mathrm{~F}_{2}$ recombinants 184 between them. The $\mathrm{F}_{2: 3}$ families of these recombinants were tested for powdery mildew resistance 185 and then used for genotyping by the newly developed polymorphic markers. From 102 SSR and 186 InDel primer pairs designed according to the WEW Zavitan (v2.0) and Chinese Spring reference 187 genomes, nine polymorphic markers were developed and integrated into the genetic linkage map 188 of MlWE74 after genotyping all the 76 recombinants (Tables S1 and S2). Finally, MlWE74 was 189 narrowed down into a $0.25 \mathrm{cM}$ genetic interval franked by markers $W G G B D 412$ and 190 WGGBH346 (Fig. 2c and d). Molecular marker WGGBD425 co-segregated with MlWE74 in the 191 WE74 and XZ population (Table S1; Fig. 2c and d; Fig. S1a).

\section{Gene annotation of the MIWE 74 genomic region}

193 The flanking markers $W G G B D 412$ and $W G G B H 346$ were used to identify the corresponding 194 genomic region of the WEW Zavitan (v2.0) reference genome sequence. Finally, MlWE74 was 195 delimited to an approximate $799.9 \mathrm{~kb}$ physical interval. Eight protein coding genes in this 196 physical interval were predicted with gene density of 10 genes $\mathrm{Mb}^{-1}$ (Fig. 2e). These predicted 197 genes included 2 phosphoglycerate mutase-like proteins (TRIDC2BG005010 and 198 TRIDC2BG005040), 5 NBS-LRR disease resistance proteins (TRIDC2BG005090, 
alpha/beta hydrolases protein (TRIDC2BG005120). It has an obvious NBS-LRR gene cluster in

201 the mapping region of $M l W E 74$.

Micro-collinearity analysis of the MIWE74 locus among tetraploid and hexaploid wheat

The two flanking markers $W G G B D 412$ and $W G G B H 346$ were used to search against the durum wheat cv. Svevo reference genome and hexaploid wheat genomes, including Chinese Spring,

Fielder, Julius_MAGIC3, Landmark, Jagger, ArinalFor, Mattis, Longreach Lancer, Mace,

Norin61 and spelt wheat PI 190962, to define the corresponding physical intervals of locus

MlWE74 in these genomes. The collinear relationship of the protein-coding genes in these intervals revealed highly micro-collinearity among tetraploid and hexaploid wheat genomes

(Table S3). Six genes, TRIDC2BG005010, TRIDC2BG005040, TRIDC2BG005090, TRIDC2BG005100, TRIDC2BG005110, TRIDC2BG005110, and TRIDC2BG005230, in Zavitan genome were syntenic among different genomes, whereas TRIDC2BG005120 and TRIDCOUG006500 were only present in Zavitan (Fig. 3; Table S4).

\section{Geographical distribution analysis of MlWE74}

The distribution of MlWE74 locus was investigated by screening the geographically diverse accessions of wild emmer wheat using the co-segregating marker $W G G B D 425$. The positive amplicon was found in $15 \mathrm{WEW}$ accessions that were mainly present in the region of Rosh Pinna and Amirim in Israel belong to the northern WEW population of Israel (Fig. 4; Table S5). The frequency of MlWE74 is only 3.3\% in 461 wild emmer wheat accessions tested. Powdery mildew 
resistant to Bgt E09 (Table S6).

\section{Comparative analysis of $M I W E 74, P m 26$ and $M I I W 170$}

Two powdery mildew resistance genes, $\operatorname{Pm} 26$ and MlIW170 derived from wild emmer wheat were located on chromosome 2BS (Rong et al. 2000; Liu et al. 2012). MlIW170, an incompletely dominant resistance gene, was identified and mapped to the distal region of chromosome 2BS by flanking markers $W G G C 1323$ and $W G G C 9140$ covering the physical interval Chr2B_Zavitan v2.0: 26.41-27.25 Mb (Liang et al. 2015), whereas the dominant gene MlWE74 was mapped on Chr2B_Zavitan v2.0: $25.48-26.28 \mathrm{Mb}$. The physical intervals of MlWE74 and MlIW170 are different, but overlapping. The recessive gene Pm26, co-segregating with marker Xcau516, is considered to be located in the same genomic region or be allelic to MlIW170 (Liu et al. 2012; Liang et al. 2015). We compared three resistant parents, WE74, IW170 and Pm26 lines by inoculating with $10 \mathrm{Bgt}$ isolates collected from different regions of China. The results demonstrated that IW170 conferred highly resistant to all the 10 isolates at the level of IT 0; and IT 1. We also found that isolates 9-43, 12-82, E21 and 46-30 virulent to wheat line WE74 and isolates 9-43, 12-50, 12-82, and E21 virulent to the wheat line Pm26 (Table S7). Isolates 12-50, 12-82, and 46-30 showed differential infection type between lines WE74 and Pm26. In addition, the MlWE74 co-segregated marker WGGBD425 failed to amplify the target DNA band on IW170 and Pm26 lines (Fig. S1b).

\section{Discussion}

\section{Comparison of MIWE74 with known powdery mildew resistance genes on 2BS}

A dominant powdery mildew resistance gene MlWE74 derived from wild emmer wheat was identified and finely mapped to a $799.9 \mathrm{~kb}$ genomic region on chromosome $2 \mathrm{BS}$ according to the 
reference genome of WEW cv. Zavitan (v2.0) (Fig. 2). Up to now, eight powdery mildew resistance genes in wheat are reported on chromosome arm 2BS, including three permanently designated genes Pm26 (Rong et al. 2000), Pm42 (Hua et al. 2009), Pm68 (He et al. 2020) and five temporarily designated loci MlIW170 (Liu et al. 2012), Ml5323 (Piarulli et al. 2012), PmL962 (Shen et al. 2015), pmWE99 (Ma et al. 2016b), and MlIW39 (Qiu et al. 2021). The minimum mapping interval of MlWE74 corresponds to the physical region of Chr2B_Zavitan v2.0: $25.48-26.28 \mathrm{Mb}$ in the reference genome of WEW cv. Zavitan (v2.0) (Fig. 5a and c). The smallest physical intervals of the other six powdery mildew resistance genes, Pm42, Pm68, Ml5323, PmL962, pmWE99 and MlIW39 are Chr2B_Zavitan v2.0: 62.24-118.92 Mb, 20.73-22.24 Mb, 22.00-25.47 Mb, 7.03-23.09 Mb, distal terminal-118.92 Mb, 21.95-22.24 Mb, origin with MlWE74. Moreover, allelism test showed that resistance genes Pm26 and Ml5323 are not allelic (Piarulli et al. 2012). The recessive gene pmWE99, originated from wheat-Thinopyrum intermedium, was mapped between chromosome 2BS distal terminus to marker Xgwm 148 . MlWE74 is a dominant powdery mildew resistance gene derived from wild emmer wheat. Hence, MlWE74 is different from those known genes on chromosome 2BS according to their difference in physical locations, effects and origins.

Powdery mildew resistance gene MlIW170 derived from wild emmer wheat was located on the physical interval Chr2B_Zavitan v2.0: 26.41-27.25 Mb in the reference genome (Fig. 5h). The physical interval of MlIW170 is different from the region of MlWE74, Chr2B_Zavitan v2.0: 
Xcau516 was developed from Xwg516 co-segregated with MlIW170 in an $\mathrm{F}_{2}$ population. These results indicate that Pm26 and MlIW170 are likely to be identical, or allelic (Liang et al. 2015). MlIW170 is an incomplete dominant gene, and Pm26 is a recessive gene, whereas MlWE74 is a dominant gene. The reactions of the three genes to $10 \mathrm{Bgt}$ isolates revealed different infection types (Table S7). The MlWE74 co-segregated marker WGGBD425 also detected different amplification pattern in Pm26 and MlIW170, indicating sequence divergence in the genomic intervals harboring the three genes (Fig. S1b). However, those differences may be resulted from variation in genetic background and polyploidy level difference between IW170 and WE74. We suppose that MlWE74, MlIW170 and pm26 may be identical or allelic, which needs future clarification by gene cloning.

\section{Genomic structure and micro-collinearity analysis of the MIWE74 locus}

The genomic region of MlWE74 (799.9 kb) according to the reference genome of WEW $\mathrm{cv}$. Zavitan (v2.0) corresponds to the physical intervals from $430.1 \mathrm{~kb}$ to $491.5 \mathrm{~kb}$ in the genomes of Svevo, Chinese Spring, Fielder, Julius_MAGIC3, Landmark, Jagger, ArinalFor, Mattis and PI 190962, and from 1,663.9 $\mathrm{kb}$ to $1,669.8 \mathrm{~kb}$ in the genomes of Longreach Lancer, Mace and Norin61 (Table S3; Fig 3). Since the protein-coding genes are relatively conserved in those genomes, the physical region difference from $400 \mathrm{~kb}$ to $800 \mathrm{~kb}$, and from $800 \mathrm{~kb}$ to $1,600 \mathrm{~kb}$ may mainly resulted from transposons and retrotransposons amplifications in those genomes, together with some NBS-LRR gene duplications.

Five genes (TRIDC2BG005090, TRIDC2BG005100, TRIDC2BG005110, TRIDC0UG006500, and TRIDC2BG005230) encode NBS-LRR resistance proteins have been annotated in the genomic interval of MlWE74. This indicates that MlWE74 is located in an NBS-LRR gene cluster. 
Up to date, 33 of 42 cloned race-specific resistance genes against fungal pathogens in wheat, barley, rye, and wild relatives are NBS-LRR resistance genes (Sánchez-Martín et al. 2021). Nine out of the 13 cloned powdery mildew resistance genes, $\operatorname{Pm} 3$ (Yahiaoui et al. 2004), Pm8 (Hurni et al. 2013), Pm2 (Sánchez-Martín et al. 2016), Pm17 (Singh et al. 2018), Pm60 (Zou et al. 2018), Pm21 (He et al.2018; Xing et al. 2018), $P m 5 e$ (Xie et al. 2020), $P m 41$ (Li et al. 2020), and Pmla (Hewitt et al. 2020), belong to the NBS-LRR resistance genes family. Therefore, the NBS-LRR resistance genes in the physical interval could serve as candidates of MlWE74 for further characterization.

\section{Geographical distribution of MlWE74 and potential value in wheat breeding}

Wild emmer wheat is a valuable source in improving both durum and common wheat due to its direct ancestry and rich genetic diversity (Nevo et al. 2014). It is mainly distributed in Israel, Syria, Jordan, Lebanon, south-east Turkey, northern Iraq, and western Iran (Nevo et al. 2014).

We used 461 accessions of wild emmer wheat, representing a wide range of ecogeographic distribution in Near-Eastern Fertile Crescent natural populations, to profile the distribution of MlWE74. A low frequency of MlWE74 was detected in the region of Rosh Pinna and Amirim in considered to be the southernmost extension with higher and cooler elevation (up to 1600-1900 m) and favorable climatic conditions for disease development (Li et al. 2020b). The pathogens environment of high selective pressure facilitates the co-evolution of disease-resistant genes. The absence of MlWE74 in the WEW natural populations from southeastern Turkey, where wheat is believed to be domesticated, suggests that MlWE74 may not participate in the process of gene transfer into cultivated wheat during wheat domestication and polyploidization. Therefore, 
MlWE74 derived from WEW would be a valuable resource for disease resistance. The co-segregating molecular marker $W G G B D 425$ could serve as an efficient, unique and convenient tool for marker assisted selection in wheat breeding program.

Acknowledgements We are grateful to Prof. Tsomin Yang and Qixin Sun for providing the wheat line WE74. This work was financially supported by the National Natural Science Foundation of China (32101735).

\section{Author contribution statement}

WH, ZYL and MML designed the experiments. KYZ, MML, HBW, DYZ, LLD, QHW, YXC, JZX, PL, GHG, HZZ, PPZ, BBL, WLL, LD, QFW, JHZ, WLH, LQG, RGW, and CGY performed the experiments, conducted fieldwork, analyzed data, and performed Bgt inoculation. KYZ, MML, WH, HJL and ZYL wrote the paper. All authors read, revised, and approved the manuscript.

\section{Compliance with ethical standards}

323 Conflict of interest The authors declare that they have no conflict of interest.

\section{Data availability statement}

All data generated or analysed during this study are included in this published article and its supplementary information files. 


\section{References}

Appels R, Eversole K, Feuillet C, Keller B, Rogers J, Stein N, Pozniak CJ, Choulet F, Distelfeld A, Poland J et al. (2018) Shifting the limits in wheat research and breeding using a fully annotated reference genome. Science 361: 661-673

Ben-David R, Xie W, Peleg Z, Saranga Y, Dinoor A, Fahima T (2010) Identification and mapping of $P m G 16$, a powdery mildew resistance gene derived from wild emmer wheat. Theor Appl Genet 121:499-510

Blanco A, Gadaleta A, Cenci A, Carluccio AV, Abdelbacki AMM, Simeone R (2008) Molecular mapping of the novel powdery mildew resistance gene Pm36 introgressed from Triticum turgidum var. dicoccoides in durum wheat. Theor Appl Genet 117:135-142

Chen XM, Luo YH, Xia X, Xia LQ, Chen X, Ren ZL, He Z, Jia J (2005) Chromosomal location of powdery mildew resistance gene Pm16 in wheat using SSR marker analysis. Plant Breed $124: 225-228$

Cowger C, Mehra LK, Arellano C, Meyers E, Murph JP (2018) Virulence differences in Blumeria graminis f. sp. tritici from the central and eastern United States. Phytopathology $108: 402-411$

Devi KD, Punyarani K, Singh NS, Devi HS (2013) An efficient protocol for total DNA extraction from the members of order Zingiberales-suitable for diverse PCR based downstream applications. Springerplus 2:669

Geng M, Zhang J, Peng F, Liu X, Lv X, Mi Y, Li Y, Li F, Xie C, Sun Q (2016) Identification and mapping of MlIW30, a novel powdery mildew resistance gene derived from wild emmer wheat. Mol Breed 36:130 
He H, Liu R, Ma P, Du H, Zhang H, Wu Q, Yang L, Gong S, Liu T, Huo N et al. (2020) Characterization of Pm68, a new powdery mildew resistance gene on chromosome 2BS of Greek durum wheat TRI 1796. Theor Appl Genet 134:53-62

He H, Zhu S, Zhao R, Jiang Z, Ji Y, Ji J, Qiu D, Li H, Bie T (2018) Pm21, encoding a typical CC-NBS-LRR protein, confers broad spectrum resistance to wheat powdery mildew disease. Mol Plant 11:879-882

Hewitt T, Muller MC, Molnar I, Mascher M, Holusova K, Simkova H, Kunz L, Zhang J, Li J, Bhatt D et al. (2020) A highly differentiated region of wheat chromosome 7AL encodes a Pmla immune receptor that recognizes its corresponding AvrPmla effector from Blumeria graminis. New Phytol 229:2812-2826

Hua W, Liu Z, Zhu J, Xie C, Yang T, Zhou Y, Duan X, Sun Q, Liu Z (2009) Identification and genetic mapping of $p m 42$, a new recessive wheat powdery mildew resistance gene derived from wild emmer (Triticum turgidum var. dicoccoides). Theor Appl Genet 119:223-230

Hurni S, Brunner S, Buchmann G, Herren G, Jordan T, Krukowski P, Wicker T, Yahiaoui N, Mago R, Keller B (2013) Rye Pm8 and wheat Pm3 are orthologous genes and show evolutionary conservation of resistance function against powdery mildew. Plant J 76:957969

Ji X, Xie C, Ni Z, Yang T, Nevo E, Fahima T, Liu Z, Sun Q (2008) Identification and genetic mapping of a powdery mildew resistance gene in wild emmer (Triticum dicoccoides) accession IW72 from Israel. Euphytica 159:385-390

Krattinger SG, Lagudah ES, Spielmeyer W, Singh RP, Huerta-Espino J, McFadden H, Bossolini E, Selter LL, Keller B (2009) A putative ABC transporter confers durable resistance to 
Lander ES, Green P, Abrahamson J, Barlow A, Daly K (1987) MAPMAKER: an interactive computer package for constructive primary genetic linkage maps of experimental and natural populations. Genomics 16:224-230

Li G, Fang T, Zhang H, Xie C, Li H, Yang T, Nevo E, Fahima T, Sun Q, Liu Z (2009) Molecular identification of a new powdery mildew resistance gene Pm41 on chromosome 3BL derived from wild emmer (Triticum turgidum var. dicoccoides). Theor Appl Genet 119:531-539

Li M, Dong L, Li B, Wang Z, Xie J, Qiu D, Li Y, Shi W, Yang L, Wu Q et al. (2020) A CNL protein in wild emmer wheat confers powdery mildew resistance. New Phytol 228:10271037

Liang Y, Zhang D, Ouyang S, Xie J, Wu Q, Wang Z, Cui Y, Lu P, Zhang D, Liu Z et al. (2015) Dynamic evolution of resistance gene analogs in the orthologous genomic regions of powdery mildew resistance gene MlIW170 in Triticum dicoccoides and Aegilops tauschii. Theor Appl Genet 128:1617-1629

Liu R, Meng J (2003) MapDraw: A Microsoft Excel macro for drawing genetic linkage maps based on given genetic linkage data, Hereditas 25:317-321

Liu Z, Sun Q, Ni Z, Nevo E, Yang T (2002) Molecular characterization of a novel powdery mildew resistance gene $P m 30$ in wheat originating from wild emmer. Euphytica 123:21-29

Liu Z, Sun Q, Ni Z, Yang T (1999) Development of SCAR markers linked to the Pm21 gene conferring resistance to powdery mildew in common wheat. Plant Breed 118:215-219

Liu Z, Zhu J, Cui Y, Liang Y, Wu H, Song W, Liu Q, Yang T, Sun Q, Liu Z (2012) Identification and comparative mapping of a powdery mildew resistance gene derived from wild emmer 
Ma P, Xu H, Han G, Luo Q, Xu Y, Zhang X, An D, Li L, Sun Y (2016b) Characterization of a segregation distortion locus with powdery mildew resistance in a wheat-Thinopyrum intermedium introgression line WE99. Plant Dis 100:1541-1547

Maccaferri M, Harris NS, Twardziok SO, Pasam RK, Gundlach H, Spannagl M, Ormanbekova D,

Mohler V, Zeller FJ, Wenzel G, Hsam SLK (2005) Chromosomal location of genes for resistance to powdery mildew in common wheat (Triticum aestivum L. em Thell.). 9. gene MlZec1 from the Triticum dicoccoides-derived wheat line Zecoi-1. Euphytica 142:161-167 ecological, pathological and allozyme associations. Euphytica 53:121-130

Moore JW, Herrera-Foessel S, Lan C, Schnippenkoetter W, Aylife M, Huerta-Espino J, Lillemo M, Viccars L, Milne R, Periyannan S et al. (2015) A recently evolved hexose transporter variant confers resistance to multiple pathogens in wheat. Nat Genet 47:1494-1498

Moseman JG, Nevo E, El-Morshidy MA, Zohary D (1984) Resistance of Triticum dicoccoides collected in Isreal to infection with Erysiphe gramminis tritici. Euphytica 33:41-47

Nevo E, Gerechter-Amitai ZK, Beiles A (1991) Resistance of wild emmer wheat to stem rust:

Nevo E (2014) Evolution of wild emmer wheat and crop improvement. J Syst Evol 52:673-696 

Fine physical and genetic mapping of powdery mildew resistance gene MlIW172 originating from wild emmer (Triticum dicoccoides). PLoS ONE 9:e100160

Parks R, Carbone I, Murph JP, Marshall D, Cowger C (2008) Virulence structure of the eastern US wheat powdery mildew population. Plant Dis 92:1074-1082

Piarulli L, Gadaleta A, Mangini G, Signorile MA, Pasquini M, Blanco A, Simeone R (2012) Molecular identification of a new powdery mildew resistance gene on chromosome 2BS from Triticum turgidum ssp. dicoccum. Plant Sci 196:101-106

Qiu L, Liu N, Wang H, Shi X, Li F, Zhang Q, Wang W, Guo W, Hu Z, Li H et al. (2021) Fine mapping of a powdery mildew resistance gene MlIW39 derived from wild emmer wheat (Triticum turgidum ssp. dicoccoides). Theor Appl Genet 134:2469-2479

Reader SM, Miller TE (1991) The introduction into bread wheat of a major gene for resistance to powdery mildew from wild emmer wheat. Euphytica 53:57-60

Rong JK, Millet E, Manisterski J, Feldman M (2000) A new powdery mildew resistance gene: introgression from wild emmer into common wheat and RFLP-based mapping. Euphytica $115: 121-126$

Sánchez-Martín J, Keller B (2021) NLR immune receptors and diverse types of non-NLR proteins control race-specific resistance in Triticeae. Curr Opin Plant Biol 62:102053

Sánchez-Martín J, Steuernagel B, Ghosh S, Herren G, Hurni S, Adamski N, Vrána J, Kubaláková M, Krattinger SG, Wicker T et al (2016) Rapid gene isolation in barley and wheat by mutant chromosome sequencing. Genome Biol 17:1-7

Sato K, Abe F, Mascher M, Haberer G, Gundlach H, Spannagl M, Shirasawa K, Isobe S (2021) 
Chromosome-scale genome assembly of the transformation-amenable common wheat cultivar 'Fielder'. DNA Res 28:1-7

Shen XK, Ma LX, Zhong SF, Liu N, Zhang M, Chen WQ, Zhou YL, Li HJ, Chang ZJ, Li X et al. (2015) Identification and genetic mapping of the putative Thinopyrum intermedium-derived dominant powdery mildew resistance gene PmL962 on wheat chromosome arm 2BS. Theor Appl Genet 128:517-528

Singh RP, Singh PK, Rutkoski J, Hodson DP, He XY, et al. (2016) Disease impact on wheat yield potential and prospects of genetic control. Aannu Rev Phytopathol 54:303-322

Singh SP, Hurni S, Ruinelli M, Brunner S, Sanchez-Martin J, Krukowski P, Peditto D, Buchmann G, Zbinden H, Keller B (2018) Evolutionary divergence of the rye $P m 17$ and $P m 8$ resistance genes reveals ancient diversity. Plant Mol Biol 98:249-260

Walkowiak S, Gao L, Monat C, Haberer G, Kassa MT, Brinton J, Ramirez-Gonzalez RH, Kolodziej MC, Delorean E, Thambugala D et al. (2020) Multiple wheat genomes reveal global variation in modern breeding. Nature 588:277-283

Xie J, Guo G, Wang Y, Hu T, Wang L, Li J, Qiu D, Li Y, Wu Q, Lu P et al. (2020) A rare single nucleotide variant in Pm5e confers powdery mildew resistance in common wheat. New Phytol 228:1011-1026

Xie W, Ben-David R, Zeng B, Distelfeld A, Röder MS, Dinoor A, Fahima T (2012) Identification and characterization of a novel powdery mildew resistance gene $P m G 3 M$ derived from wild emmer wheat, Triticum dicoccoides. Theor Appl Genet 124:911-922

Xing L, Hu P, Liu J, Witek K, Zhou S, Xu J, Zhou W, Gao L, Huang Z, Zhang R et al. (2018) Pm21 from Haynaldia villosa encodes a CC-NBS-LRR protein conferring powdery mildew 
resistance in wheat. Mol Plant 11:874-87

461

462

463

464

465

466

467

468

469

470

471

472

473

474

475

476

477

478

479

480

Yahiaoui N, Srichumpa P, Dudler R, Keller B (2004) Genome analysis at different ploidy levels allows cloning of the powdery mildew resistance gene $P m 3 b$ from hexaploid wheat. Plant $\mathbf{J}$ $37: 528-538$

Yin H, Fang X, Li P, Yang Y, Hao Y, Liang X, Bo C, Ni F, Ma X, Du X et al. (2021) Genetic mapping of a novel powdery mildew resistance gene in wild emmer wheat from "Evolution Canyon" in Mt. Carmel Israel. Theor Appl Genet 134:909-921

Zhang D, Zhu K, Dong L, Liang Y, Li G, Fang T, Guo G, Wu Q, Xie J, Chen Y et al. (2019) Wheat powdery mildew resistance gene Pm64 derived from wild emmer (Triticum turgidum var. dicoccoides) is tightly linked in repulsion with stripe rust resistance gene Yr5. Crop J

$$
7: 761-770
$$

Zhang H, Guan H, Li J, Zhu J, Xie C, Zhou Y, Duan X, Yang T, Sun Q, Liu Z (2010) Genetic and comparative genomics mapping reveals that a powdery mildew resistance gene Ml3D232 originating from wild emmer co-segregates with an NBS-LRR analog in common wheat (Triticum aestivum L.). Theor Appl Genet 121:1613-1621

Zhu TT, Wang L, Rodriguez JC, Deal KR, Avni R, Distelfeld A, Mcguire PE, Dovorak J, Luo MC (2019) Improved genome sequence of wild emmer wheat Zavitan with the aid of optical maps. G3-Genes Genom Genet 9:619-624

Zou S, Wang H, Li Y, Kong Z, Tang D (2018) The NB-LRR gene Pm60 confers powdery mildew resistance in wheat. New Phytol 218:298-309 
Table 1 Segregation ratios of MlWE74 in WE74 $\times$ XZ populations

\begin{tabular}{|c|c|c|c|c|c|c|c|}
\hline \multirow{2}{*}{ Cross } & \multirow{2}{*}{ Generation } & \multirow{2}{*}{$\begin{array}{l}\text { Number of the } F_{2} \\
\text { plants or } F_{2: 3} \text { families }\end{array}$} & \multicolumn{3}{|c|}{ Observed ratio } & \multirow[t]{2}{*}{ Expected ratio } & \multirow[t]{2}{*}{$\chi^{2}$} \\
\hline & & & HR & Seg & HS & & \\
\hline WE74/XZ & $\mathrm{F}_{2}$ & 165 & 120 & & 45 & $3: 1$ & 0.455 \\
\hline WE74/XZ & $\mathrm{F}_{2: 3}$ & 165 & 38 & 82 & 45 & $1: 2: 1$ & 0.515 \\
\hline
\end{tabular}

485

HR: homozygous resistant, Seg: segregating (heterozygous resistant), and HS: homozygous susceptible

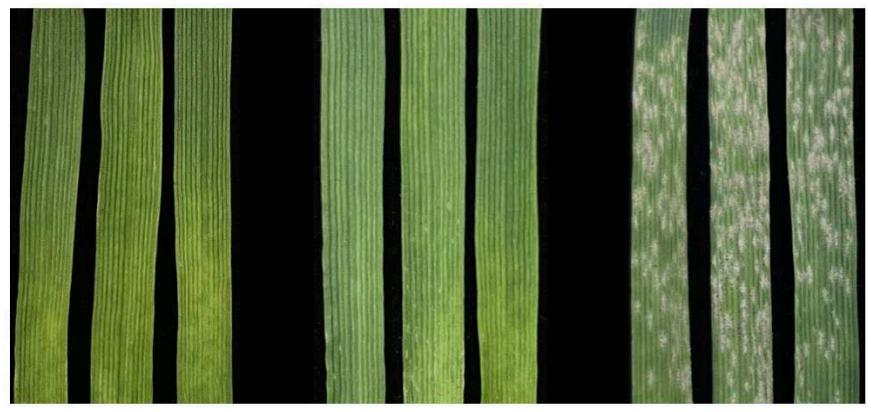

Figure 1 Phenotypes of WE74, WE74 $\times \mathrm{XZ} \mathrm{F}_{1}$ and $\mathrm{XZ}$ at two weeks post-inoculation with $B g t$ 490 isolate E09. 


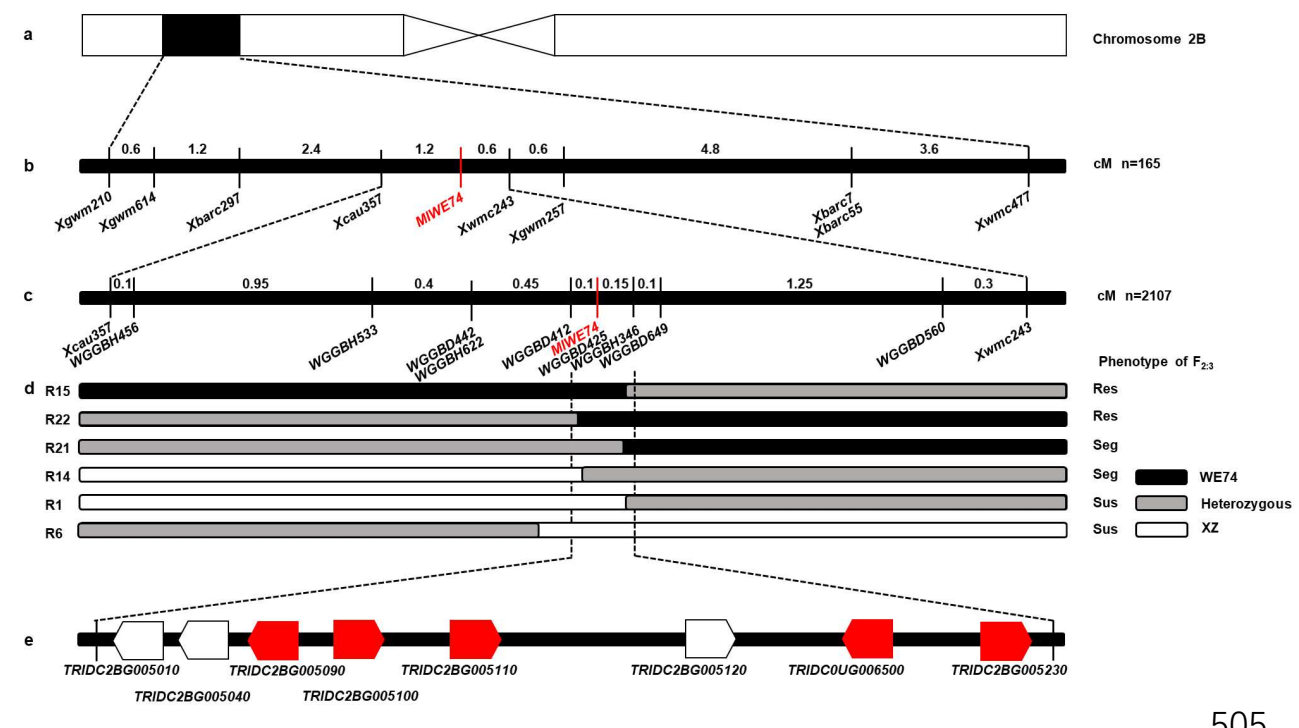

506 Figure 2 Fine mapping of the powdery mildew resistance gene MlWE74. a Physical location of 507 MlWE74 in chromosome 2B. b Genetic linkage map of MlWE74. Numbers above the line are 508 genetic distances between adjacent markers in cM. c High-resolution genetic linkage map of 509 MIWE74. d Genotypes and phenotypes of the six relevant recombinant events. Recombinant 510 events and phenotypes are indicated at the left and right, respectively. Res, Seg and Sus represent 511 resistant, segregation and susceptible, separately. White, black and gray blocks indicate 512 homozygous segments from WE74, homozygous segments from XZ and heterozygous segments, 513 respectively. e Annotated genes in the physical mapping interval of the MlWE74 locus. Red 514 pentagons represent NBS-LRR proteins related to disease resistance. 


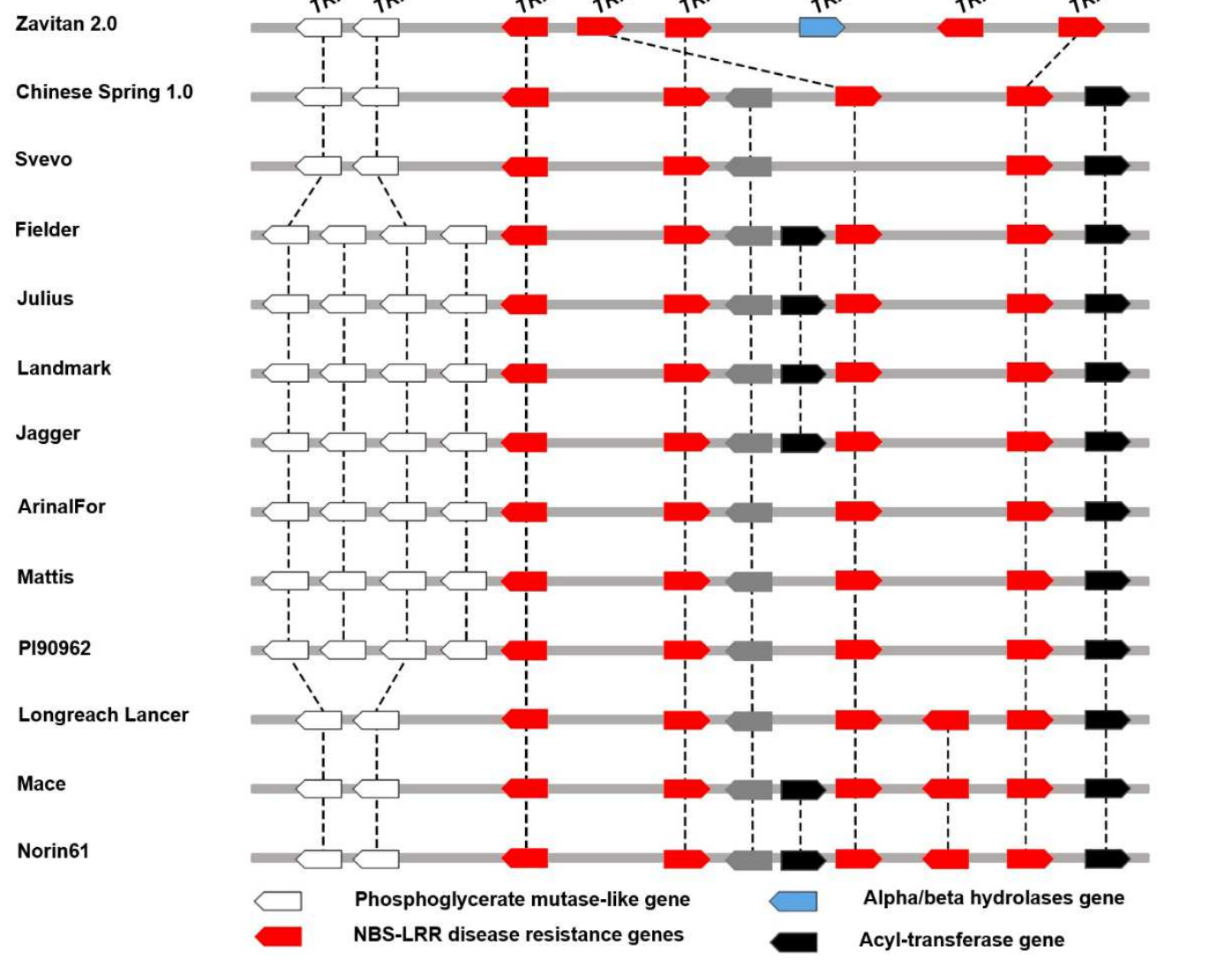

Figure 3 Micro-collinearity of the genomic region of MlWE74 between wild emmer, durum and hexaploid wheat. Orthologous genes are linked by lines. 


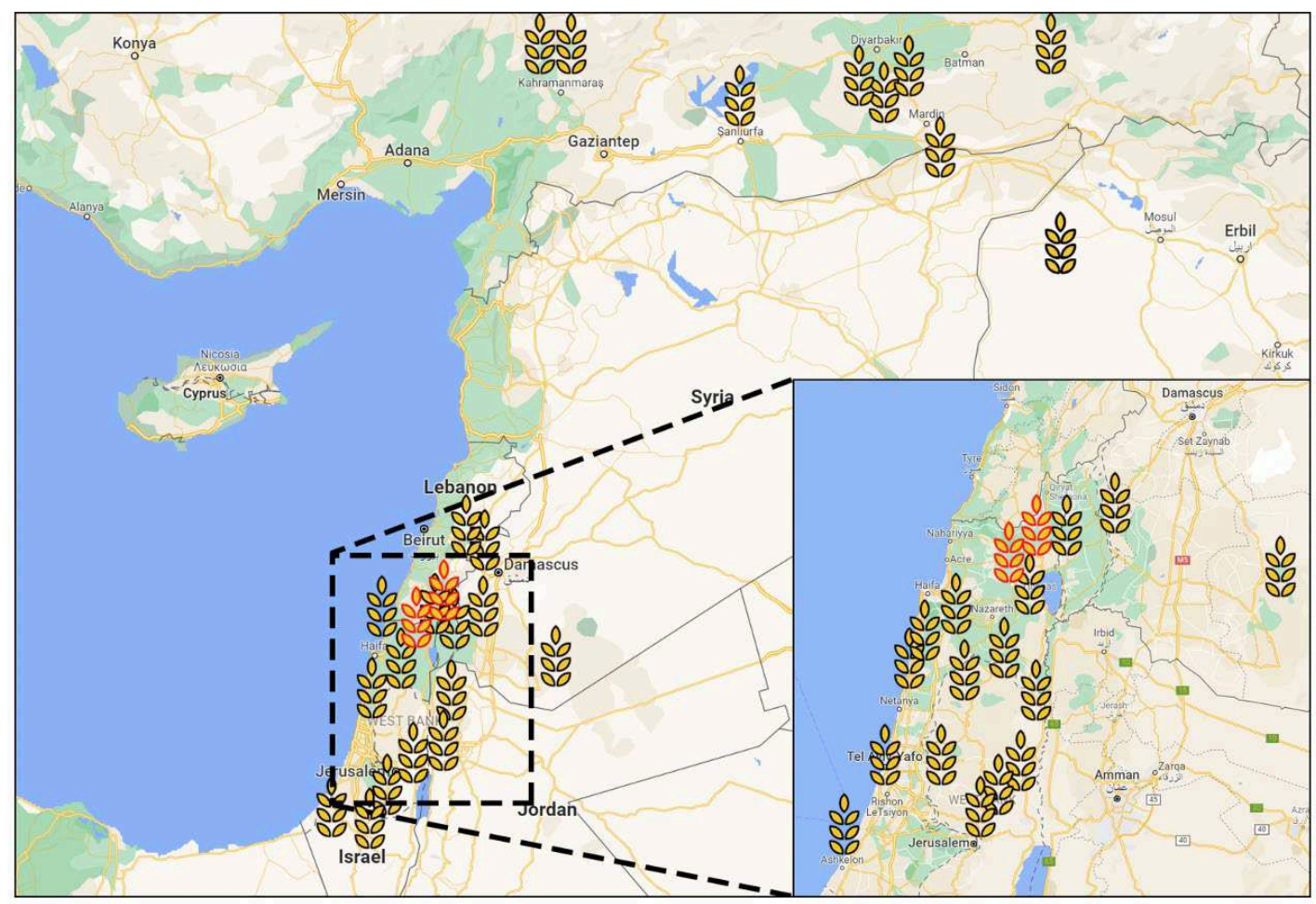

521 Figure 4 Geographic distribution of MlWE74 in WEW populations from the Fertile Crescent 522 region. Black spikes indicate absence of MlWE74; red spikes represent the presence of MlWE74, distributed only in the regions of Rosh Pinna and Amirim in Israel. 


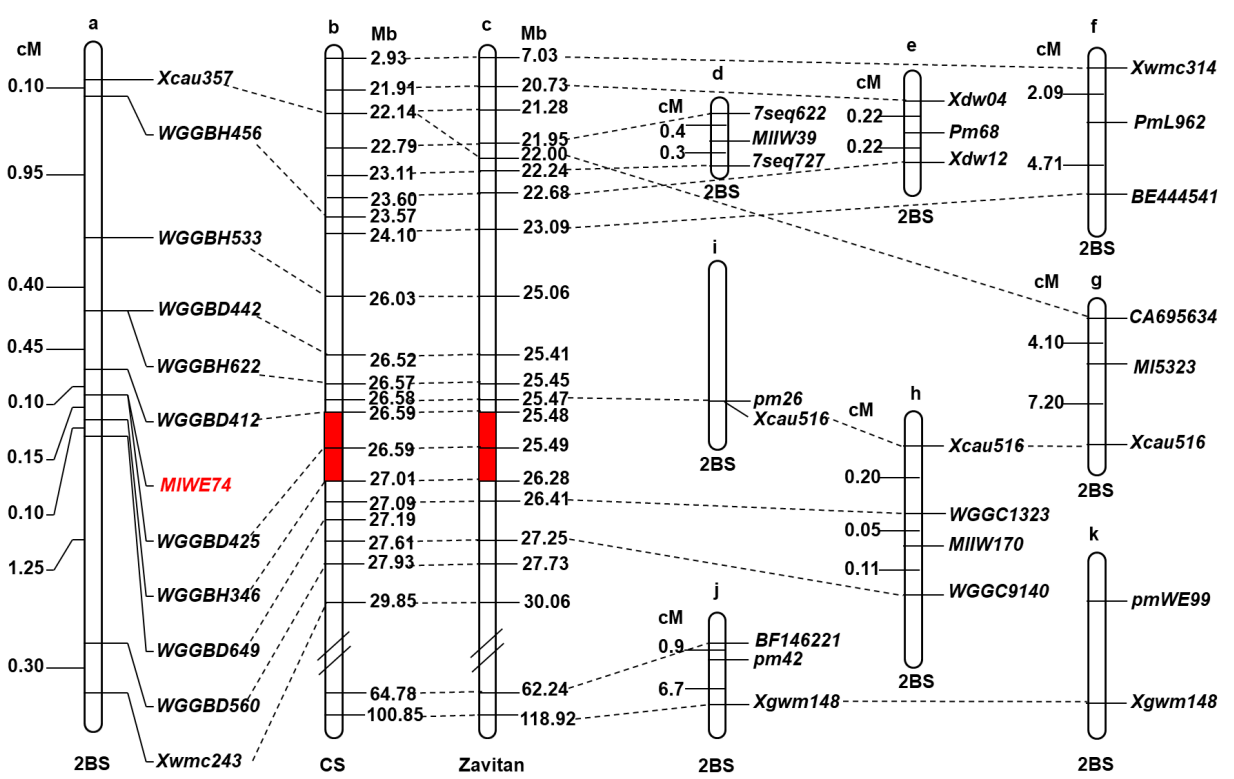

540

541 Figure 5 Comparison of genetics linkage map of MLWE74 (a) with those reported powdery mildew resistance genes MlIW39 (d), Pm68 (e), PmL962 (f), Ml5323 (g), MlIW170 (h), pm26 (i), pm42 (j) and pmWE99 (k) using the linked markers Xcau516 and Xgwm148 as anchors. Physical map of the MlWE74 region based on the Chinese Spring reference genome sequence (IWGSC RefSeq v1.0) (b) and WEW accession Zavitan reference genome sequence (v2.0) (c), physical locations in $\mathrm{Mb}$ are shown at the right. 
a

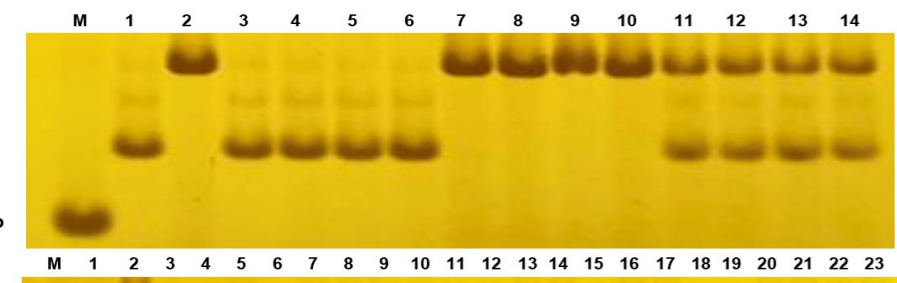

b

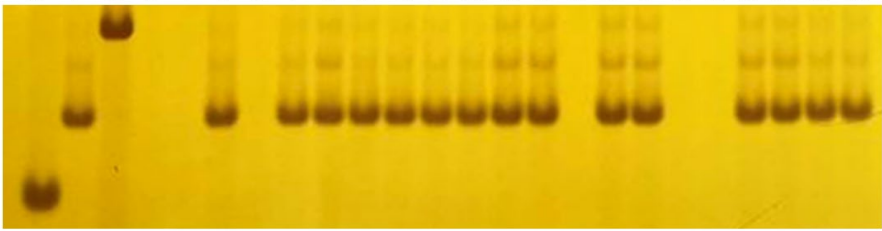

Figure S1 PCR amplification patterns of co-segregated marker WGGBD425. a Lanes 1 and 2, WE74 and XZ; lanes 3-6, homozygous resistant lines; lanes 7-10, homozygous susceptible lines; lanes 11-14, heterozygous resistant lines in WE74/XZ population. b Lanes 1-4, WE74, XZ, IW170 and Pm26; lanes 5-14, IW11-IW20; lanes 15-23, IW61-IW69.

Table S1 Primers used in mapping of MlWE74.

Table S2 Genotypes of markers for the 76 recombinant $F_{2: 3}$ families derived from WE74/XZ cross.

Table S3 The interval between flanking markers $W G G B D 412$ and $W G G B H 346$ in the genomes of different wheat varieties.

Table S4 Annotated genes in the physical interval of different wheat genomes (- means no matched gene).

Table S5 Haplotype variation of the MlWE74 co-segregated marker WGGBD425 in wild emmer wheat.

Table S6 Powdery mildew response of 15 wild emmer wheat accessions carrying MlWE74 to Bgt $\mathrm{E} 09$.

Table S7 Infection types of WE74, Pm26 and IW170 to $10 \mathrm{Bgt}$ isolates. 


\section{Supplementary Files}

This is a list of supplementary files associated with this preprint. Click to download.

- Tables.xlsx 